\title{
INTRA-FAMILIAL AND EXTRA-FAMILIAL RISK FACTORS ASSOCIATED WITH CRYPTOSPORIDIUM PARVUM INFECTION AMONG CHILDREN HOSPITALIZED FOR DIARRHEA IN GOIÂNIA, GOIÁS, BRAZIL
}

\author{
MARIA DAS GRAÇAS CABRAL PEREIRA, EDWARD ROBERT ATWILL, ALVERNE PASSOS BARBOSA, \\ SIMONNE ALMEIDA E SILVA, AND MARCO TULIO ANTONIO GARCÍA-ZAPATA \\ Department of Population Health and Reproduction, Veterinary Medicine Teaching and Research Center, School of Veterinary \\ Medicine, University of California-Davis, Tulare, California; Departamento de Microbiologia, Imunologia, Parasitologia, e Patologia \\ and Departamento de Medicina Tropical, Saúde Coletiva e Dermatologia, Instituto de Patologia Tropical e Saúde Pública, \\ Universidade Federal de Goiás, Goiânia, Goiás, Brazil
}

\begin{abstract}
A cross-sectional study was conducted for assessing the prevalence of and risk factors associated with Cryptosporidium parvum in diarrheic children who were hospitalized in Goiânia, capital of Goiás State in Brazil. A crude prevalence of $14.4 \%$ (64 of 445) was observed using a direct immunfluorescent assay (DFA), but the true prevalence was $18.7 \%$ ( 83 of 445 ) when a gold standard of immunomagnetic separation was used in combination with the DFA. Infection was more predominant in children less than 24 months old (odds ratio [OR] $=0.50,90 \%$ confidence interval $[\mathrm{CI}]=0.36-0.68, P=0.0001)$, and males were 2.2 times more at risk for infection when compared with females $(\mathrm{OR}=2.2,90 \% \mathrm{CI}=0.13-3.8, P=0.01)$. The socioeconomic, intra-familial, and environmental factors associated with cryptosporidiosis were day care attendance, household children with diarrhea up to 30 days prior to the interview, contact with surface water within past 30 days prior to the interview, dwelling distance from a body of water, and the late rainy season $(P<0.10)$. C. parvum was not associated with the parent's occupation, household sleeping arrangements, number of caregivers, breast-fed children, diet and type of food hygiene, source and type of treatment of drinking water, presence of sewage, and animal exposure $(P>0.10)$. Although weight was not found to be associated with infection, children infected with $C$. parvum weighed on average $2.0 \%$ less than children not infected with $C$. parvum $(P>0.10)$. Thus, $C$. parvum is an important etiologic agent of childhood diarrhea and should be identified in routine parasitologic tests of diarrheal stool samples.
\end{abstract}

\section{INTRODUCTION}

Studies done in all continents have shown that the protozoal parasite Cryptosporidum parvum is a common enteric pathogen that is associated with diarrheal disease and occasional death among young children, especially in developing countries. ${ }^{1,2}$ Clinical symptoms associated with acute illness include diarrhea, vomiting, abdominal cramps, anorexia, fever, and weight loss. ${ }^{1,3}$ Reported prevalences of $C$. parvum infection among children have varied from less than $1 \%$ to more than $30 \%$ on a population basis. ${ }^{1,4-7}$ In regions endemic for C. parvum where this parasite actively circulates in a community, the risk of symptomatic infection during early childhood is in part a function of a child's exposure to biologic sources of this parasite (e.g., intra-familial and extra-familial infected contacts, infected domestic animals) and exposure to mechanical vectors such as contaminated food, water, and household surfaces. ${ }^{2-4,6}$ Therefore, reducing a child's exposure to these biologic sources and reducing the parasitic load from mechanical vectors could reduce the annual incidence of this disease in susceptible children.

In Brazil, up to $17 \%$ of cases of childhood diarrhea have been shown to be associated with $C$. parvum infection. ${ }^{8-11}$ Several studies have been conducted in urban populations among diarrheic children in Brazil, but the majority of this work did not examine preventable risk factors associated with clinical cryptosporidiosis or based the conclusions on univariate associations that were susceptible to confounding. ${ }^{8-10} \mathrm{~A}$ study conducted in children residing within a Brazilian urban slum or "favela" determined that low birth weight and geographic location were risk factors for acquisition of symptomatic infection with Cryptosporidium. ${ }^{3}$ The ability of breastfeeding to protect against early childhood cryptosporidiosis has been inconclusive. Prospective studies in Peru and Brazil have not documented any protective effect. ${ }^{3,12} \mathrm{~A}$ case-control study in Guinea-Bissau found a decreased odds of infection with this dietary practice. ${ }^{2}$ A cross-sectional study in four townships in Zambia identified an increased odds of cryptosporidiosis among breast-fed diarrheic children. ${ }^{6}$

In Goiás, a midwestern state of Brazil, routine testing for $C$. parvum has historically been limited to individuals infected with human immunodeficiency virus (HIV), and is uncommon for general cases of childhood diarrhea. Thus, little is known about the medical ecology of this parasite in this region of Brazil, how children are exposed, and whether such factors as breast-feeding and contact with zoonotic sources function of alter the prevalence of cryptosporidiosis. Given this lack of substantial information regarding cryptosporidiosis in Goiás and our poor knowledge of the epidemiology of this parasite among children in this region, we conducted a cross-sectional epidemiologic study in diarrheic children who were hospitalized in Goiânia, the capital of Goiás, to identify intra-familial and extra-familial risk factors for infection with C. parvum.

\section{MATERIAL AND METHODS}

Subjects. This cross-sectional study was conducted in six major pediatric hospitals located in Goiânia, Brazil between the last week of August 1998 and the first week of May 1999. The study population was composed of children ranging in age from two weeks to 10 years old who had been hospitalized primarily due to diarrhea and dehydration at hospital wards or medical units managed by the government national health system (Sistema Único de Saúde-SUS). Patients are admitted regardless of their point of origin. Diarrhea was defined as loose or watery stools in a 24-hour period that was still present when the fecal specimen was collected at the hospital. Exclusion groups were patients who developed diarrhea after 
admission to the hospital wards and patients who were hospitalized with diarrhea but with a medical diagnose of food intolerance. A total of 445 cases were referred to this study by either the pediatrician or nurse responsible for the hospital wards or oral rehydration ward units. None of the children in this study was HIV-positive.

Information retrieval. Following informed written consent, the study nurse administered a comprehensive questionnaire to the child's primary custodian. The questionnaire included items on 1) host factors: age, sex, and weight; 2) sociodemographic and intra-familial factors: city of origin, type of dwelling, parent's occupation, number of household members stratified by age, number of household members stratified by age with gastrointestinal symptoms at the time of the survey or at most 30 days prior to the interview, household members sleeping arrangements, number of caretakers for the index child, day care attendance including day care size and number of hours and days the child spent at day care; 3) zoonotic factors: number of pets owned by the household, occurrence of diarrhea among pets up to 30 days prior to the interview, contact with livestock, presence of a dairy farm within $1 \mathrm{~km}$ of the dwelling, and whether a household member worked at an animal agriculture facility; and 4) environmental factors: season, diet (consumption of raw salad items, consumption of non-peeled fruits, consumption of milk), food hygiene, source and treatment of drinking water, proximity of a body of raw water (e.g., river or lake) or sewage effluent canal near the dwelling, and recent direct body contact with running (e.g., river) or standing water (e.g., lake or swimming pool).

Specimen collection and detection of $C$. parvum oocysts. A single fecal sample was collected from each patient by parents or guardians and placed into a disposable plastic cup. Fecal characteristics were directly observed, classified, and recorded by the study nurse as either loose stool with blood, loose stool with no blood, liquid stool with blood, or liquid stool with no blood. The sample was then preserved by adding $10 \%$ formalin at a $1: 1$ volume ratio.

One gram of each diarrheic fecal sample was washed through four-fold surgical cotton gauze. The fecal suspension was centrifuged at $1,000 \times g$ for 10 minutes, the supernatant was aspirated, and the sediment was resuspended 1:1 (v/v) in sterile distilled water. Using a disposable 10- $\mu$ L loop, fecal suspensions were smeared onto glass slides and dried overnight for immunofluorescent microscopy. ${ }^{13}$ Detection of oocysts was performed using the direct immunofluorescent assay (Cryptosporidium/Giardia detection kit; Meridian Diagnostic, Inc., Cincinnati, $\mathrm{OH}$ ). The entire fecal smear was examined for $C$. parvum oocysts at $\times 400$ magnification, and the sample was positive if one or more oocysts were detected; otherwise the sample was negative. ${ }^{13}$

The direct immunofluorescent assay, as performed by experienced microscopists, has been shown to be highly specific and reasonably sensitive for human clinical samples. ${ }^{14-17}$ To generate an estimate of the true prevalence of $C$. parvum infection in this population of diarrheic children, we needed estimates of the sensitivity and specificity of the direct immunofluorescent assay. Based on four previous human studies $^{14-17}$ and our examination of this assay in livestock fecal material $1^{13,18}$ we assumed that the specificity was approximately $100 \%$ in our laboratory. To generate an estimate of the sensitivity of this assay, we estimated the likelihood of false-negative results for detection of C. parvum in this popu- lation of children using 20 negative diarrheic stool samples and a gold standard of immunomagnetic separation (Dynal, Inc., Lake Success, NY) in combination with immunofluorescent microscopy. ${ }^{13}$ It has been observed that immunomagnetic separation is highly efficacious in enumerating low concentrations of cryptosporidial oocysts in fecal and environmental samples. ${ }^{13,19}$

Statistical analysis. Fixed effects logistic regression was used to test and quantify the association between the various putative risk factors (host, sociodemographic and intrafamilial, zoonotic, environmental) and the odds of shedding C. parvum. $^{20} \mathrm{~A}$ forward-stepping algorithm was used, with a two-sided $P$ value $\leq 0.10$ for the inclusion of the factor in the model using the likelihood ratio test. Goodness-of-fit for the final model was calculated using the deviance with a chisquare test performed on the appropriate degrees of freedom to determine $P$ values. ${ }^{20}$ Multiple linear regression was used to determine if $C$. parvum infection was associated with acute weight loss relative to non-C. parvum cases. ${ }^{21} \mathrm{We}$ modeled $\log _{10}$ (body weight in kilograms) as a function of $\log _{10}$ (age in years $)+\operatorname{sex}+C$. parvum infection status, with all two-way interactions also tested for significance.

\section{RESULTS}

Prevalence of $\boldsymbol{C}$. parvum infection. Among diarrheic children $\leq 10$ years of age who had been taken to hospital wards or dehydration medical units in Goiânia, Brazil, the apparent prevalence of $C$. parvum infection was $14.4 \%$ (64 of 445$)$. We estimated the true prevalence of patent $C$. parvum infection among our study population of diarrheic children using the equation $^{22}$

$$
\text { True prevalence }=\frac{\text { Apparent prevalence }+S p-1}{S e+S p-1}
$$

whereby the apparent prevalence was estimated as $14.4 \%$ and the sensitivity $(\mathrm{Se})$ and specificity $(S p)$ were the diagnostic attributes of the direct immunofluorescent assay when applied to our study population of children with diarrhea. We used a consensus estimate from the literature of $100 \%$ for the specificity of this immunofluorescent assay. ${ }^{14-17}$ To estimate the test sensitivity, we examined 20 negative diarrheic stools using a gold standard method (immunomagnetic separation) coupled with immunofluorescent microscopy, and found that one sample (5\%) contained a low concentration of C. parvum oocysts. Using this $5 \%$ estimate for the likelihood of falsenegative results, we estimated that approximately 19 of the 381 negative samples $(381 \times 0.05=19)$ may have had low levels of oocysts; therefore, the sensitivity for this assay was approximately $77 \%$ (64 of 83 ) and the adjusted or true prevalence of patent $C$. parvum infection in this population of diarrheic children was estimated to be $18.7 \%$ (83 of 445 ).

Host factors. The age of the child was negatively associated with the odds of $C$. parvum infection because the odds of $C$. parvum infection decreased approximately 0.50 for each additional year of age (odds ratio $[\mathrm{OR}]=0.50,90 \%$ confidence interval $[\mathrm{CI}]=0.36-0.68, P=0.0001$ ) (Table 1). $78 \%$ of infected children were less than 24 months of age, with infected children ranging in age from 2.5 to 47 months (Table 2). The odds of $C$. parvum infection was 2.2 times higher for males compared with females $(\mathrm{OR}=2.2,90 \% \mathrm{CI}=1.3-3.8$, 
TABLE 1

Fixed effects logistic regression model for patent Cryptosporidium parvum infection in children hospitalized with diarrhea in Goiânia, Brazil

\begin{tabular}{|c|c|c|c|}
\hline Factor & $\begin{array}{l}\text { Prevalence of shedding } \\
\text { C. parvum oocysts } \\
\text { No. positive/no. tested }\end{array}$ & $\begin{array}{l}\text { Odds ratio } \\
\text { (90\% confidence interval) }\end{array}$ & $\begin{array}{l}\text { Likelihood ratio } \\
\text { test }(P \text { value })^{*}\end{array}$ \\
\hline Age $\dagger$ & Not applicable & $0.50(0.36-0.68)$ & 0.0001 \\
\hline Sex & & & 0.01 \\
\hline Male & $46 / 261(18 \%)$ & $2.2(1.3-3.8)$ & \\
\hline Female & $18 / 184(10 \%)$ & 1.0 & \\
\hline Day care attendance & & & 0.06 \\
\hline Yes & $15 / 71(21 \%)$ & $2.1(1.1-3.8)$ & \\
\hline No & 49/373 (13\%) & 1.0 & \\
\hline Number of household children with diarrhea $\dagger$ & Not applicable & $1.9(1.4-2.7)$ & 0.001 \\
\hline Presence of a body of water & & & 0.01 \\
\hline Yes & $16 / 168(10 \%)$ & $0.45(0.26-0.78)$ & \\
\hline No & $48 / 276(17 \%)$ & 1.0 & \\
\hline Season & & & 0.002 \\
\hline Dry $\$$ & $8 / 87(9.0 \%)$ & 1.0 & \\
\hline Early rainfall & $32 / 278(12 \% 0$ & $1.2(0.56-2.4)$ & \\
\hline Late rainfall & $24 / 79(30 \%)$ & $3.7(1.7-8.3)$ & \\
\hline Exposure to lake, river, or creek water & & & 0.10 \\
\hline Yes & $4 / 20(20 \%)$ & $3.4(1.1-10.6)$ & \\
\hline No $\ddagger$ & $59 / 414(14 \%)$ & 1.0 & \\
\hline
\end{tabular}

$P=0.01)$. The prevalence of C. parvum infection for girls and boys decreased by $70 \%$ and $14 \%$ from the first to the second year of life, respectively, with no $C$. parvum infections detected among girls after 24 months of age (Table 2). When the analysis was adjusted for age and sex, diarrheic children infected with $C$. parvum weighed on average $2.0 \%$ less (up to $280 \mathrm{~g}$ of body weight) than diarrheic children not infected with $C$. parvum, but this association between $C$. parvum infection and weight loss was not statistically significant $(P=0.14)$.

Sociodemographic and intra-familial factors. Being placed in day care with other children during the past 30 days was associated with a 2.1 times greater odds of $C$. parvum infection when compared with children who did not attend day care centers $(\mathrm{OR}=2.1,90 \% \mathrm{CI}=1.1-3.8, P=0.06)$. The number of children in day care (with 0 for children not attending day care), which served as an alternative designation for exposure to day care, was also significant (Table 3) (OR

TABLE 2

Age- and sex-specific distribution of patent Cryptosporidium parvum infection in children hospitalized with diarrhea in Goiânia, Brazil

\begin{tabular}{lc}
\hline $\begin{array}{l}\text { Age groups } \\
\text { (months) }\end{array}$ & $\begin{array}{c}\text { Prevalence of } C \text {. parvum infection } \\
\text { no. positive/no. tested (\%) }\end{array}$ \\
\hline$\leq 6$ & $10 / 80(12.50 \%)$ \\
Boys & $7 / 45(15.60 \%)$ \\
Girls & $3 / 35(8.60 \%)$ \\
$>6-12$ & $33 / 133(24.81 \%)$ \\
Boys & $20 / 74(27.03 \%)$ \\
Girls & $13 / 59(22.03 \%)$ \\
$>12-24$ & $17 / 117(14.53 \%)$ \\
Boys & $15 / 77(19.50 \%)$ \\
Girls & $2 / 40(5.00 \%)$ \\
$>24-48$ & $4 / 71(5.63 \%)$ \\
Boys & $4 / 42(9.50 \%)$ \\
Girls & $0 / 29(0.00 \%)$ \\
$>48-120$ & $0 / 41(0 \%)$ \\
Boys & $0 / 21(0 \%)$ \\
Girls & $0 / 20(0 \%)$ \\
\hline
\end{tabular}

$=1.01,90 \% \mathrm{CI}=1.001-1.02, P=0.07)$, with the odds of cryptosporidiosis increasing about $10 \%$ for every additional 10 children in day care. The number of days/week and hours/ day spent at the day care centers was not significant $(P>$ $0.10)$. Children who lived in families with other young children ( $\leq 10$ years old) were at greater risk for $C$. parvum infection $(P<0.10)$ than children in families without young children. However, this factor became insignificant $(P=$ 0.001 ) when the number of household children with diarrhea up to 30 days prior to the interview was introduced into the logistic regression model. The odds of $C$. parvum infection increased for the index child as the number of other household children with diarrhea increased $(\mathrm{OR}=1.9,90 \% \mathrm{CI}=$ 1.4-2.7) (Table 4). Other sociodemographic or intra-familial factors such as number of healthy or diarrheic adults or teenagers in the household, city of origin, parent's occupation, sleeping arrangements, and number of caregivers attending the case (changing diapers) were not associated with the odds of $C$. parvum infection in this study population. Ninety eight percent of the children in the study came from urban areas; $55 \%$ of the sample population lived in Goiânia and $46 \%$ resided in other cities either within the state or from the neighborhood states of Mato Grosso, Pará, Tocantins, and Bahia.

Environmental factors. The odds of $C$. parvum infection among diarrheic children was almost four-fold greater during the latter part of rainy season: January through March $(\mathrm{OR}=$

TABLE 3

Distribution of patent Cryptosporidium parvum infection in children hospitalized with diarrhea in Goiânia, Brazil, stratified by number of children attending day care

\begin{tabular}{lc}
\hline $\begin{array}{l}\text { Size of day care (no. of children) } \\
\text { that child attended }\end{array}$ & $\begin{array}{c}\text { Prevalence of } C \text {. parvum infection } \\
\text { no. positive/no. tested (\%) }\end{array}$ \\
\hline Did not attend day care & $49 / 373(13.1 \%)$ \\
$1-40$ & $5 / 28(17.9 \%)$ \\
$41-80$ & $5 / 17(29.4 \%)$ \\
$\geq 81$ & $5 / 15(33.3 \%)$ \\
\hline
\end{tabular}


TABLE 4

Distribution of patent Cryptosporidium parvum infection in children hospitalized with diarrhea in Goiânia, Brazil, stratified by number of children with diarrhea in the household, excluding the index case of diarrhea

\begin{tabular}{cc}
\hline $\begin{array}{c}\text { Number of children in addition to the index case } \\
\text { that had diarrhea within the past 30 days }\end{array}$ & $\begin{array}{c}\text { Prevalence of } C \text {. parvum infection } \\
\text { No. positive/no. tested (\%) }\end{array}$ \\
\hline 0 & $37 / 311(11.9 \%)$ \\
1 & $19 / 111(17.9 \%)$ \\
2 & $4 / 12(33.3 \%)$ \\
$3-5$ & $4 / 9(44.4 \%)$ \\
\hline
\end{tabular}

3.7, $90 \%$ CI $=1.7-8.3, P=0.002)$ when compared with the odds of $C$. parvum infection among diarrheic children during the dry season (August, September, April, and May) (Table 1 ), with the crude prevalence of $C$. parvum infection reaching a peak of $44 \%$ in January (Figure 1 ). The odds of $C$. parvum infection was not significantly different during the dry season compared with the early part of the rainy season: October through December $(P>0.10)$. The odds of $C$. parvum infection was not associated with consumption of fresh fruits or vegetables, source of water supply, nor significantly different for children who were breast-fed compared with those who were given other dietary sources of milk (e.g., synthetic or bovine). Recreational contact with natural sources of surface water (lake, river, or creek) within the past 30 days was associated with a higher odds of $C$. parvum infection $(\mathrm{OR}=3.4$, $90 \%$ CI $=1.1-10.6, P=0.1)$ compared with children who were exposed to only swimming pools or who had no aquatic recreational activity. Curiously, children whose household dwelling was within $50 \mathrm{~m}$ of a body of water (raw surface water source or sewage effluent canal) were at less risk for $C$. parvum infection compared with children who lived more distant from these bodies of water $(\mathrm{OR}=0.45,90 \% \mathrm{CI}=$ $0.26-0.78, P=0.01$ ).

Zoonotic factors. None of the factors indicative of zoonotic exposure were associated with the odds of $C$. parvum infec- tion $(P>0.10)$, despite reasonably large percentages of the study population documenting animal exposure. For example, $36 \%$ of the children in the study had recently visited a livestock operation prior to their interview; 37\% lived within 1 $\mathrm{km}$ of a dairy farm; $57 \%$ owned a dog; $27 \%$ owned a cat. Diarrhea was present in $11 \%$ of the dogs and $0.7 \%$ of the cats of these households.

Goodness-of-fit for the multivariate logistic regression model was deviance $=276$ on 397 degrees of freedom; $P=1.0$.

\section{DISCUSSION}

This study characterized the prevalence of and potential intra-familial and extra-familial risk factors for C. parvum infection in diarrheic children hospitalized in Goiânia, Brazil. Assuming a specificity of $100 \%$ and a sensitivity of $77 \%$, for our diagnostic assay as applied to our study population, we estimated an adjusted prevalence of patent $C$. parvum infection of $18.7 \%$. Reported prevalences of $C$. parvum infection in children from other Latin American countries have ranged from $3.9 \%$ in Argentina, $4.3 \%$ in Costa Rica, $10.8 \%$ in Venezuela, $11.2 \%$ in Ecuador, $13.8 \%$ in Guatemala, and $16.7 \%$ in Haiti. $^{7,23}$ The reported range of cryptosporidial infection in Brazil has varied from $1.1 \%$ to $17.4 \% .^{3,8-11}$ Such prevalences were generated by less sensitive diagnostic tests compared with the direct immunofluorescent assay used in our study, ${ }^{14-17}$ but differences in the age distribution of the study population, combined with differences in exposure to risk factors, likely contribute to the inter-study differences in the observed prevalence of infection among Brazilian children. Our adjusted prevalence of $18.7 \%$, which was based on sensitivity data from a gold standard of immunomagnetic separation in combination with immunofluorescent microscopy, ${ }^{13}$ was similar to that observed for urban Zambian children ${ }^{6}$ and lower than the $29.6 \%$ reported for the State of Puebla, Mexico. ${ }^{24}$

The prevalence of $C$. parvum infection was strongly associated with a variety of intra-familial and extra-familial risk

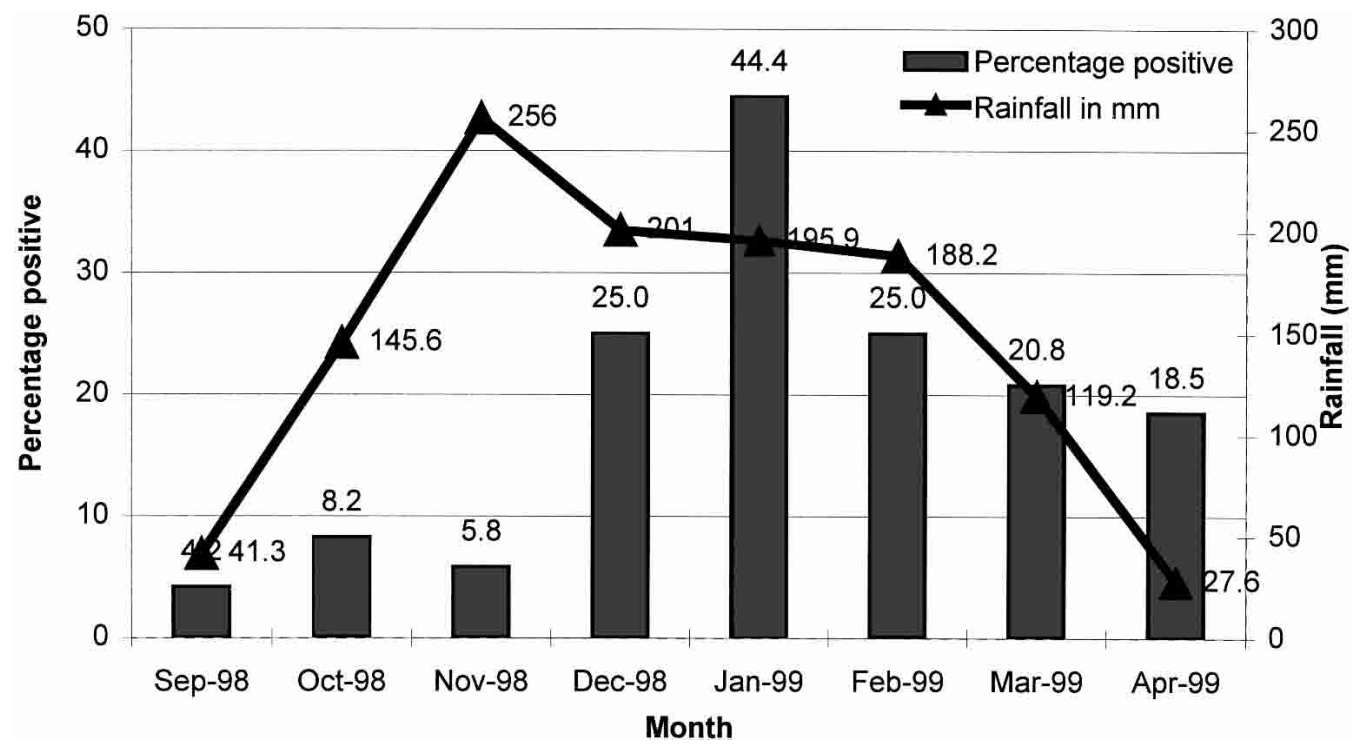

FIGURE 1. Seasonal distribution of Cryptosporidium parvum in children hospitalized with diarrhea compared with monthly rainfall totals (mm) in Goiânia, Brazil, September 1998-April 1999. 
factors, ranging from the age and sex of the child to recreational exposure to rivers and lakes. Cryptosporidium parvum infection in our study population was limited to children $\leq 4$ years of age, with $78 \%$ of infections limited to children $\leq 24$ months of age. This age-associated pattern of young children being at highest risk of infection was similar to that found in the city of São Paulo. ${ }^{10}$ When the analysis was adjusted for the age of the child, boys were at higher risk of $C$. parvum infection compared with girls. This was similar to patterns observed in Guinea-Bissau ${ }^{2}$ and among Bedouin infants in Israel. ${ }^{4}$ Moreover, C. parvum infection occurred up to 47 months of age for boys, compared with only 21 months of age for girls. Given the fact that most childhood infections occurred within the first 24 months of life, and assuming that immune competency is similar for boys and girls at this age, an unmeasured intra-familial factor appears to have been functioning to expose infant boys or to protect infant girls in our study population. For example, differential rates or differential intensities of personal contact between the infant and the various caregivers may be different for boys compared with girls. If primary or other caregivers (e.g., older siblings) function as biologic sources of C. parvum or as a mechanical vectors of $C$. parvum, increased contact with male infants may result in an increased risk of infection. The investigators who conducted the research in Guinea-Bissau and Israel $^{2,4}$ did not offer explanations as to why male infants and children were at higher risk of acquiring cryptosporidiosis compared with females. Additional observational studies are needed to clarify the reasons for this association.

Attending day care centers within 30 days of becoming hospitalized for diarrhea was associated with an elevated risk of cryptosporidiosis. This is consistent with previous studies in both developed and developing countries. ${ }^{25,26}$ Furthermore, we found that the risk of cryptosporidiosis was positively associated with the total number of children at the day care facility, with the crude prevalence of $C$. parvum infection reaching $33 \%$ for children attending large day care centers (Table 3). This high prevalence of active infection among diarrheic children who had been attending day care underscores the importance of not allowing children who develop diarrhea to continue to attend day care. Outbreaks of C. parvum among children attending day care have been associated with secondary cases and asymptomatic infections among intra-familial contacts. ${ }^{1}$ Within the limitations of a crosssectional study design, we did not find evidence for a higher prevalence of self-reported diarrhea among children $\leq 10$ years of age who resided within the same household as the index case who had attended day care compared with households whose children did not attend day care. Specifically, the potential interaction between day care attendance and cases of diarrhea among other child household members was not significant in our multivariate logistic regression model $(P=$ 0.17 ) for $C$. parvum infection. Moreover, among the 64 cases of $C$. parvum infection in our study population, the percentage of households with additional childhood cases of diarrhea was $27 \%$ for families where the index case attended day care, compared with $47 \%$ for families where the index case did not attend day care. Using Fisher's exact test, the prevalence of diarrhea was not significantly different between these two exposure groups (two-sided $P=0.16$ ). These findings suggest that while $C$. parvum is likely to be transmitted between infected and susceptible children while attending day care, these cases of day care-associated $C$. parvum were not associated with an increased prevalence of diarrhea among other children in the same household. Intra-familial transmission of C. parvum is well documented, with up to $19 \%$ of household members acquiring this parasite following a single index case. $^{3,27,28}$ This lack of an association between cases of day care-associated $C$. parvum and secondary cases of diarrhea may be the consequence of our cross-sectional study design, in that insufficient time had accrued for secondary cases to develop. Alternatively, households that have historically relied on day care facilities for many of the children could result in higher levels of previous exposure to C. parvum among the household's children, thereby leading to higher levels of resistance to clinical cases of secondary transmission. Interestingly, we found that the likelihood of $C$. parvum infection among our study population was much higher for children from households experiencing one or more additional cases of childhood diarrhea within the past 30 days. Specifically, the prevalence of $C$. parvum infection was $12 \%, 17 \%, 33 \%$, and $44 \%$ for diarrheic children from households with either no, one, two, or three or more cases of recent diarrhea, respectively (Table 4). This suggests that a subset of the cases of cryptosporidiosis in our study population may have been secondary to a recent intra-familial case of cryptosporidiosis. Of the 132 diarrheic children who were from households in which one or more cases of diarrhea had occurred in the past 30 days, $20 \%$ (27 of 132) were found to be shedding C. parvum oocysts. In contrast, only $12 \%$ of diarrheic children from households with no recent history of childhood diarrhea had C. parvum. Exposure to day care, the presence of a nearby body of water, and the sex of the child were not significantly associated with $C$. parvum infection among these 132 children, but the age of the child (a proxy for lack of prior exposure) and rainfall season (a broad spatio-temporal scale of exposure) remained significant.

Many studies have demonstrated a higher prevalence of $C$. parvum infection during the rainy season. . $^{3,6,8,10,29}$ Our study similarly found a significant association between the odds of C. parvum infection and the occurrence of rain (Figure 1). Similar trends were also observed in other regions of Brazil, and in Indonesia and Zambia. ${ }^{3,6,10,29}$ The biologic source(s) for $C$. parvum infection and the exact routes of transmission during these wetter months have not been well described, but the impact of rainfall has been shown to mobilize and transport $C$. parvum oocysts out of fresh fecal material and fecal slurries and across vegetated soil surfaces and through soil columns. ${ }^{30-33}$ Increased numbers of cases of $C$. parvum infection in Fortaleza and Lusaka during the rainy season were associated with contaminated drinking water supplied to these population, ${ }^{3,6}$ but source of drinking water and mode of water disinfection were not associated with the odds of $C$. parvum infection among our study population. Because the $50 \%$ infectious dose is relatively low for $C$. parvum, ranging from approximately 10 to 1,000 for healthy humans, ${ }^{34}$ oocysts could be transmitted through low levels of contaminated water or food, followed by person-to-person transmission, especially among household members. Food-borne $C$. parvum infection has been transmitted through ingestion of freshpressed apple cider, and risk factors for food-borne transmission have had been reported for consumption of stored cooked food, fresh sausages, offal, and raw milk. ${ }^{1}$ Cryptosporidium parvum has also been isolated from raw 
salad items sold at open markets in Peru. ${ }^{35}$ We found no significant associations with consumption of numerous food items (primarily vegetables and fruits), the mode of washing food items, drinking water sources, and the odds of $C$. parvum infection. Therefore, the mode of transmission for rainfallassociated $C$. parvum remains unclear.

Recreational exposure to $C$. parvum has been reported for swimming in raw water supplies (e.g., lakes) or municipal swimming pools. ${ }^{1,36}$ Similarly, we found that the exposure to either a lake, river, or creek during the past 30 days was associated with a 3.4 fold increase in the odds of infection with C. parvum. Using the final logistic regression model in Table 1 to estimate the adjusted prevalence of $C$. parvum infection associated with recreational exposure to raw surface water, we found that the prevalence of $C$. parvum infection for a four-year-old boy or girl with no day care exposure, no secondary cases of diarrhea at home, and who were not exposed to raw surface water in the past 30 days during the dry season was $1.3 \%$ and $0.6 \%$, respectively. In contrast, recreational exposure to raw surface water for similar four-year-old boys and girls was associated with a prevalence of $C$. parvum infection of $4.2 \%$ and $1.9 \%$, respectively. This results in an estimated prevalence difference of approximately 3\% for boys and $1 \%$ for girls. If we presume that accidental ingestion of contaminated raw surface water was the route of transmission in these young children, this would indicate that waterborne concentrations of $C$. parvum in these surface water supplies were sufficiently increased to be associated with a $1-3 \%$ increase in the prevalence of fecal shedding of $C$. parvum oocysts for these four-year-old children. Alternatively, because such family outings are typically associated with consumption of food items during conditions of reduced personal hygiene (e.g., picnics), other routes of transmission such as cross-contamination of foodstuffs secondary to poor handwashing after defecation are certainly possible. Curiously, the reduced odds of $C$. parvum infection associated with having the household domicile located nearby a body of water is in juxtaposition to the increased odds of $C$. parvum infection associated with recreational exposure to raw water supplies.

Neither zoonotic exposure nor breast-feeding were associated with the prevalence of C. parvum infection in our study population of diarrheic children. We had reasonable statistical power to detect zoonotic associations, given that $36 \%$ of the children in the study had visited a livestock farm prior to the hospital interview, $37 \%$ of children lived within $1 \mathrm{~km}$ of a dairy farm, 57\% owned a dog, and $27 \%$ owned a cat. A longitudinal study conducted in an urban slum in Brazil and a cross-sectional study on urban Zambian children did not find any significant association between zoonotic exposure and elevated rates or prevalences of $C$. parvum infection, ${ }^{3,6}$ but a case-control study conducted on children from Guinea-Bissau observed increased odds of clinical cryptosporidiosis associated with exposure to dogs or pigs. ${ }^{2}$ Previous observational studies that have examined the protective effects of breastfeeding on either the duration or prevalence of fecal shedding of C. parvum or on clinical cryptosporidiosis have been inconclusive..$^{2,6,37,38,39}$ Similar to our study, ingestion of breast milk of varying duration was not associated with a reduction in the prevalence or duration of infection among Peruvian children. ${ }^{37}$ In contrast, breast-feeding was found to either reduce the odds of clinical cryptosporidiosis among children in Guinea-Bissau, ${ }^{2}$ or increase the prevalence of clinical cryptosporidiosis among children from Lusaka, Zambia. ${ }^{6}$ Several of these studies relied on univariate associations between breast-feeding and the various indices of $C$. parvum infection, resulting in potentially confounded associations. Passive lacteal immunity and passive colostral immunity were not protective against experimental oral inoculations of $C$. parvum in neonatal mice and newborn calves, respectively. ${ }^{38,39}$

The results of this study clearly showed that $C$. parvum is an important etiologic agent of children hospitalized with diarrhea in Goiânia, Brazil. Thus, there is a need to include this protozoal parasite in routine parasitologic tests of children's diarrhea. The risk factors presented here could facilitate measures to minimize the burden of cryptosporidiosis in this population. To further clarify potential intra-familial and extra-familial sources of $C$. parvum for children, future efforts should determine the prevalence of $C$. parvum in domestic and farm animals located in this community, and through the use of genotyping techniques, compare isolates of C. parvum from infected children to isolates obtained from both drinking water and these potential animal reservoirs.

Acknowledgments: We thank all participating hospitals whose staff and managers provided us with access to the studied population, the study nurses from Universidade Católica de Goiás and Universidade Federal de Goiás who helped with giving the questionnaire, the Laboratório Central de Goiás for providing laboratory space, and to those whose direct and indirect contributions made this work possible.

Authors' addresses: Maria das Graças Cabral Pereira and Edward Robert Atwill, Veterinary Medicine Teaching and Research Center, School of Veterinary Medicine, University of California-Davis, Tulare, CA 93274. Alverne Passos Barbosa, Marco Tulio, Antonio García-Zapata, Departamento de Microbiologia, Imunologia, Parasitologia e Patologia, Instituto de Patologia Tropical e Saúde Pública, Universidade Federal de Goiás, Goiânia, Goiás 74605-050, Brazil. Simonne Almeida e Silva, Departamento de Medicina Tropical, Saúde Coletiva e Dermatologia, Instituto de Patologia Tropical e Saúde Pública, Universidade Federal de Goiás, Goiânia, Goiás 74605-050, Brazil.

Reprint requests: Maria das Graças Cabral Pereira, 1383 Surge III, School of Veterinary Medicine, University of California, Davis, Davis, CA 95616, Telephone: 530-754-7187, fax: 530-752-7563, e-mail: mpereira@ucdavis.edu

\section{REFERENCES}

1. Casemore DP, Wright SE, Coop RL, 1997. CryptosporidiosisHuman and Animal Epidemiology. R Fayer, ed. Cryptosporidium and Cryptosporidiosis. Boca Raton, FL: CRC Press, $65-92$.

2. Mølbak K, Aaby P, Højlyng N, da Silva AP, 1994. Risk factors for Cryptosporidium diarrhea in early childhood: a case control study from Guinea-Bissau, West Africa. Am J Epidemiol 139: 734-740.

3. Newman RD, Sears CL, Moore SR, Nataro JP, Wuhib T, Agnew DA, Guerrant RL, Lima AAM, 1999. Longitudinal study of Cryptosporidium infection in children in northeastern Brazil. $J$ Infect Dis 180: 167-175.

4. Fraser D, Dagan R, Naggan L, Greene V, El-On J, Abu-Rbiah Y, Deckelbaum RJ, 1997. Natural history of Giardia lamblia and Cryptosporidium infections in a cohort of Israeli Bedouin infants: a study of a population in transition. Am J Trop Med Hyg 57: 544-549.

5. Gosh AR, Nair GB, Dutta P, Pal SC, Sen D, 1991. Acute diarrhoeal diseases in infants aged below six months in hospital in Calcutta, India: an aetiological study. Trans $R$ Soc Trop Med Hyg 85: 796-798.

6. Nchito M, Kelly P, Sianongo S, Luo NP, Feldman R, Farthing M, 
Baboo KS, 1998. Cryptosporidiosis in urban Zambian children: an analysis of risk factors. Am J Trop Med Hyg 59: 435-437.

7. Reinthaler FF, 1989. Epidemiology of Cryptosporidiosis in children in tropical countries. J Hyg Epidemiol Microbiol 33: 505513.

8. Gennari-Cardoso ML, Costa-Cruz JM, de Castro E, Lima LM, Prudente DV, 1996. Cryptosporidium sp. in children suffering from acute diarrhea at Uberlândia city, State of Minas Gerais, Brazil. Mem Inst Oswaldo Cruz 91: 551-554.

9. Loureiro ECB, Linhares AC, Mata L, 1990. Cryptosporidiosis in children from 2 years of age, with acute diarrhea in Belém, Pará, Brazil. Mem Inst Oswaldo Cruz 84: 117-122.

10. Mangini ACS, Dias RMDS, Grisi SJFF, Escobar AM, Torres DMAGV, Zuba IPR, Quadros CMS, Chieffi PP, 1992. Parasitismo por Cryptosporidium sp em crianças com diarréia aguda. Rev Inst Med Trop Sao Paulo 34: 341-345.

11. Oshiro ET, Dorval MEC, Nunes VLB, Silva MAA, Said LAM, 2000. Prevalência do Cryptosporidium parvum em crianças abaixo de 5 anos, residentes na zona urbana de Campo Grande, MS, Brasil, 1996. Rev Soc Bras Med Trop 33: 277-280.

12. Checkley W, Gilman RH, Epstein LD, Suarez M, Diaz JF, Cabrera L, Black RE, Sterling CR, 1997. Asymptomatic and symptomatic cryptosporidiosis: their acute effect on weight gain in Peruvian children. Am J Epidemiol 145: 156-163.

13. Pereira MGC, Atwill ER, Jones T, 1999. Comparison of sensitivity of immunofluorescent microscopy to that of a combination of immunomagnetic separation and immunofluorescent microscopy for detection of Cryptosporidium parvum oocysts in adult bovine feces. Appl Environ Microbiol 65: 3236-3239.

14. Garcia LS, Shimizu RY, 1997. Evaluation of nine immunoassay kits (enzyme immunoassay and direct fluorescence) for detection of Giardia lamblia and Cryptosporidium parvum in human fecal specimens. J Clin Microbiol 35: 1526-1529.

15. Garcia LS, Shum AC, Bruckner DA, 1992. Evaluation of a new monoclonal antibody combination reagent for direct fluorescence detection of Giardia lamblia and Cryptosporidium parvum in human fecal specimens. J Clin Microbiol 30: 3255-3257.

16. Kehl KS, Cicirello H, Havens PL, 1995. Comparison of four different methods for detection of Cryptosporidium species. $J$ Clin Microbiol 33: 416-418.

17. MacPherson DW, McQueen R, 1993. Cryptosporidiosis: multiattribute evaluation of six diagnostics methods. J Clin Microbiol 31: 198-202.

18. Atwill ER, Harp JA, Jones T, Jardon PW, Checal S, Zylstra M, 1998. Evaluation of periparturient dairy cows and contact surfaces as a reservoir of Cryptosporidium parvum for calfhood infection. Am J Vet Res 59: 1116-1121.

19. Rochelle PA, de Leon R, Johnson A, Stewart MH, Wolfe RL, 1999. Evaluation of immunomagnetic separation for recovery of infectious Cryptosporidium parvum oocysts from environmental samples. Appl Environ Microbiol 65: 841-845.

20. Corp CS, 1999. LogXact 4 for windows. Cambridge, MA: Cytel Software Corp.

21. S-Plus 2000, 1999. Statistical inference for one- and two-sample problems. Guide to Statistics. Volume 1. Data Analysis Products Division. Seattle, WA: MathSoft, 165-253.

22. Schwabe CW, Reimann HP, Franti CE, 1977. Epidemiology in Veterinary Practice. Philadelphia: Lea and Febiger, 78.

23. Vergara M, Quiroga M, Grenón S, Villalba V, Pegels E, Chade M, Gonzáles C, Binsztein N, Eiguer T, Depetris A, 1992. Identification of enteropathogens in infantile diarrhea in a study performed in the city of Posadas, Misiones, República Argentina. Rev Latinoam Microbiol 34: 71-75.

24. Miller K, Duran-Pinales C, Cruz-Lopez A, Morales-Lechuga L, Taren D, Enriquez FJ, 1994. Cryptosporidium parvum in children with acute diarrhea in Mexico. Am J Trop Med Hyg 51: 322-325.

25. Addiss DG, Stewart JM, Finton RJ, Wahlquist SP, Dickerson JW, Spencer HC, Juranek DD, 1991. Giardia lamblia and Cryptosporidium infection in child day-care centers in Fulton County, Georgia. Pediatr Infect Dis J 10: 907-911.

26. Franco RM, Cordeiro NS, 1996. Giardiasis and Cryptosporidiosis in day-care centers in the municipality of Campinas, São Paulo. Rev Soc Bras Med Trop 29: 585-591.

27. Current WL, 1994. Cryptosporidium parvum: Household transmission. Ann Intern Med 120: 518-519.

28. MacKenzie WR, Schell WL, Blair KA, Addiss DG, Peterson DE, Hoxie NJ, Kazmierezak JJ, Davis JP, 1995. Massive outbreak of waterborne Cryptosporidium infection in Milwaukee, Wisconsin: recurrence of illness and risk of secondary transmission. Clin Infect Dis 21: 57-62.

29. Katsumata T, Hosea D, Wasito EB, Kohno S, Hara K, Soeparto P, Ranuh IG, 1998. Cryptosporidiosis in Indonesia: A hospitalbased study and a community based survey. Am J Trop Med Hyg 59: 628-632.

30. Atwill ER, Tate KW, George MR, McDougald NK, 1998. Transport of Cryptosporidium parvum oocysts out of fecal patties during simulated rainfall. Symposium on Rangeland Management and Water Resources. Reno, NV: American Water Resources Association, 446.

31. Mawdsley JL, Brooks AE, Merry RJ, 1996. Movement of the protozoan Cryptosporidium parvum through three contrasting soil types. Biol Fertil Soil 21: 30-36.

32. Mawdsley JL, Brooks AE, Merry RJ, Pain BF, 1996. Use of a novel titling table apparatus to demonstrate the horizontal and vertical movement of the protozoan Cryptosporidium parvum in soil. Biol Fertil Soil 23: 215-220.

33. Tate KW, Atwill ER, George MR, McDougald NK, Larsen RE, 2000. Cryptosporidium parvum mobilization and transport from livestock fecal deposits on California rangeland watersheds. J Range Managem 53: 295-299.

34. Okhuysen PC, Chappell CL, Crabb JH, Sterling CR, Dupont HL, 1999. Virulence of three different Cryptosporidium parvum isolates for healthy adults. J Infect Dis 180: 1275-1281.

35. Ortega YR, Roxas CR, Gilman RH, Miller NJ, Cabrera L, Taqueri C, Sterling CR, 1997. Isolation of Cryptosporidium parvum and Cyclospora cayetanensis from vegetables collected in markets of an endemic region in Peru. Am J Trop Med Hyg 57: 683-686.

36. Kramer MH, Sorhage FE, Goldstein ST, Dalley E, Wahlquist SP, Herwaldt BL, 1997. First reported outbreak in the United States of Cryptosporidium associated with a recreational lake. $J$ Clin Infect Dis 26: 27-33.

37. Sterling CR, Gilman RH, Sinclair NA, Cama V, Castillo R, Diaz F, 1991. The role of breast milk in protecting urban Peruvian children against Cryptosporidiosis. J Protozool 38: 23S-25S.

38. Harp JA, Woodmansee DB, Moon HW, 1989. Effects of colostral antibody on susceptibility of calves to Cryptosporidium parvum infection. Am J Vet Res 50: 2117-2119.

39. Moon HW, Woodmansee DB, Harp JA, Abel S, Ungar BL, 1988. Lacteal immunity to enteric cryptosporidiosis in mice: immune dams do not protect their suckling pups. Infect Immun 56: 649-653. 